\title{
Docking Unit Joining Omni Wheel Robot and Mobile Robot
}

\author{
Naoki Igo ${ }^{a}, *$, Daichi Fujita ${ }^{\mathrm{b}}$, Ryoma Hanabusa $^{\mathrm{c}}$, Yasuto Nagase ${ }^{\mathrm{d}}$, Satoshi Mitsuie, Toshifumi Satake ${ }^{\mathrm{f}}$ \\ a'Department of Systems, Control and Information Engineering, National Institute of Technology, Asahikawa College. Email:igo@asahikawa-nct.ac.jp \\ ${ }^{\mathrm{b}}$ Graduate School of Information, Production and Systems, Waseda University. Email:daichi0312mwam@gmail.com \\ ${ }^{\mathrm{c}}$ Advanced Course of Production System Engineering, National Institute of Technology, Asahikawa College. Email:p188014@edu.asahikawa-nct.ac.jp \\ ${ }^{\mathrm{d}}$ Advanced Course of Production System Engineering, National Institute of Technology, Asahikawa College. Email:p188012@asahikawa.kosen-ac.jp \\ e Department of Systems, Control and Information Engineering, National Institute of Technology, Asahikawa College. Email:mitui@asahikawa-nct.ac.jp \\ fDepartment of Systems, Control and Information Engineering, National Institute of Technology, Asahikawa College. Email:satake@ asahikawa-nct.ac.jp
}

\begin{abstract}
This research realizes a docking unit joining omni wheel robot and mobile robot. The omni wheel robot cannot move on rough ground. In order to move on rough ground, a mobile robot that can move with the omni wheel robot is required. The docking unit aims at a unit that can be used without remodeling omni wheel robot. The docking unit realized by this research can store the fixed part of the omni wheel robot. When omni wheel robot is mounted, the mounting surface is flat because the fixed parts are stored, and the omni wheel robot can be mounted by sliding. As a result, we designed a mechanism to connect the fixed parts to store the parts that fix the omni wheel robot. And the fixed parts with the mechanism were made.
\end{abstract}

Keywords: Docking unit, omni wheel robot, mobile robot

\section{Introduction}

In human life, robots are getting familiar. For example, there are robots to talk $[1,2]$, pet robots $[3,4]$, healing robots [5], physical ability extension robots [6-8], moving assistance robot $[9,10]$, and the like. In the human life, the ultimate form of the robot being targeted is a humanoid robot. If the robot is a humanoid, it will be possible to work with the tool just like a human being. Previous humanoid robots occupied the majority for research and commercial use, and it was a price that ordinary people can not purchase. Pepper was released from SoftBank Robotics Corp. as a humanoid robot at a price that ordinary people can purchase. Pepper moves by the omni wheel. Omni wheels are effective mobile devices when moving in various directions. However, it is difficult to freely move the floor with structurally large steps and irregularities. Therefore, Pepper can be used only within the limited space of the room. When this problem is solved, the range of use of Pepper expands. Therefore, this research realizes an extended movement unit for expanding the movement range of Pepper. The extended movement unit aims at a unit that can be used without remodeling Pepper.

\footnotetext{
${ }^{*}$ Corresponding author. Tel.: +81-166-55-8028

2-2-1-6, Shunkodai, Asahikawa, Hokkaido, Japan, 071-8142
}

\section{Omni Wheel Robot}

\subsection{Overview of Pepper}

In this research, we used Pepper as an omni wheel robot. Pepper is an inexpensive humanoid robot released by SoftBank Robotics Corp. in 2015. Figure 1 is a picture of Pepper. Pepper is a humanoid robot developed coexisting with people and focusing on communicating with people. As

Table 1. Specification of Pepper [11].

\begin{tabular}{|c|c|}
\hline Size & $1210 \times 480 \times 425[\mathrm{~mm}]$ \\
\hline Weight & $29[\mathrm{~kg}]$ \\
\hline Battery & Li-ion battery \\
\hline Head sensor & $\begin{array}{l}\text { Microphone } \mathrm{x} 4 \text {, RGB camera } \mathrm{x} 2,3 \mathrm{D} \\
\text { sensor } \mathrm{x} 1 \text {, Touch sensor } \mathrm{x} 3\end{array}$ \\
\hline Chest sensor & Gyro sensor $\mathrm{x} 1$ \\
\hline Hand sensor & Touch sensor $\mathrm{x} 2$ \\
\hline Leg sensor & $\begin{array}{l}\text { Sonar sensor x } 2 \text {, Laser sensor x6, Bumper } \\
\text { sensor x } 3 \text {, Gyro sensor x } 1\end{array}$ \\
\hline Actuator & Motor x20 \\
\hline Display & 10.1 inch touch display \\
\hline $\begin{array}{l}\text { Communication } \\
\text { method }\end{array}$ & $\begin{array}{l}\text { Wi-Fi : IEEE } 802.11 \text { a/b/g/n } \\
(2.4 \mathrm{GHz} / 5 \mathrm{GHz}), \text { Ethernet port } \mathrm{x} 1 \\
(10 / 100 / 1000 \text { base } \mathrm{T})\end{array}$ \\
\hline OS & NAOqi OS \\
\hline
\end{tabular}


a feature, it has feelings and has a tablet on the chest. Currently, Pepper is used for reception at the store, work of customer service, and communication robot at home. Table 1 is a list of basic specifications of Pepper [11].

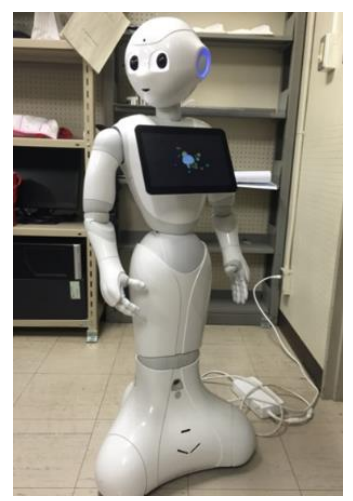

(a) Overall view

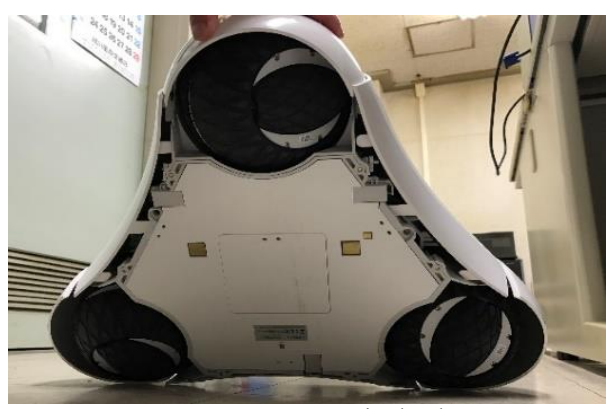

(b) Pepper's omni wheel

Figure 1. Picture of Pepper.

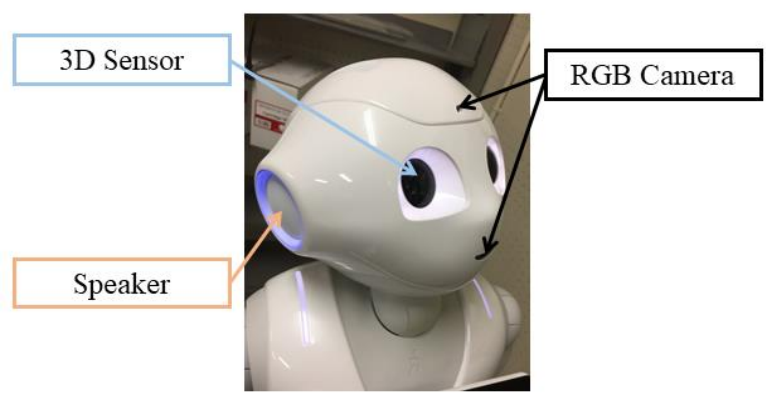

(a) Sensors on head

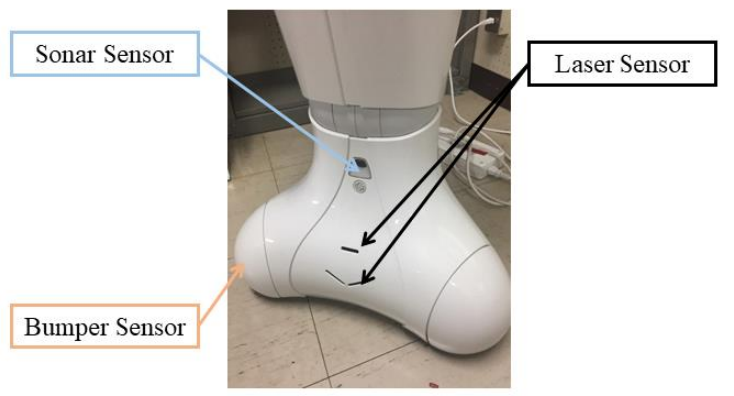

(b) Sensors on leg

Figure 2. Sensor locations of Pepper

\subsection{Sensors of Pepper}

Pepper has many sensors. In particular, sensors are concentrated on the head and the leg, and Figure 2 shows the arrangement of the various sensors. The head is equipped with cameras and the like necessary for communicating with humans. The legs are equipped with necessary sensors to avoid obstacles during movement and to keep the distance between humans and distance proper. Also, there are touch sensors on the head and hand, Pepper can get tactile sense. Gyro sensors are used to keep Pepper moving upright.

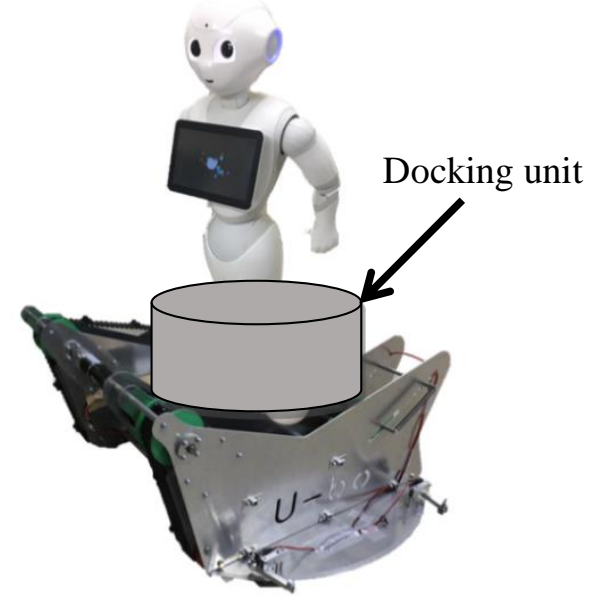

Figure 3. Combined image of Pepper and extended movement unit

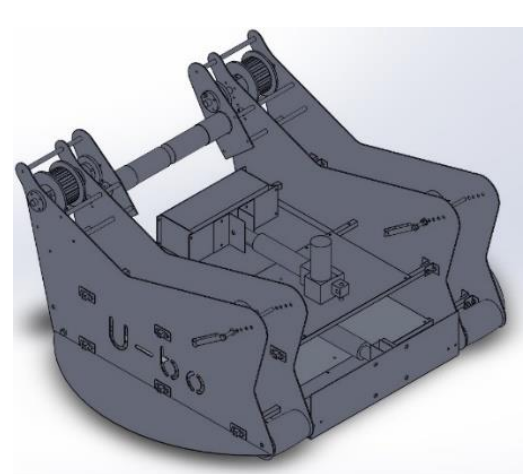

(a) Image of 3DCAD

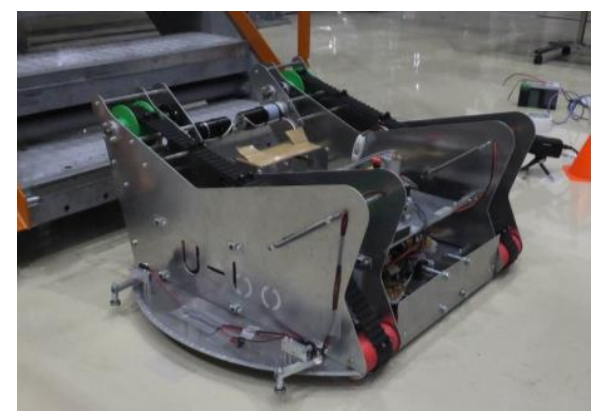

(b) Picture of mobile robot

Figure 4. Mobile robot 


\subsection{Application development environment of Pepper}

There are Choregraph, Python SDK (Software Development Kit), ROS (Robot Operating System) as environments for developing applications for Pepper. Choregraphe can develop applications for Pepper on the GUI as shown in Fig. 1. By linking prepared blocks and blocks with lines, it is possible to create Pepper's motion and develop applications easily. Application development for remote control using Choregraphe is not suitable for the characteristics of Choregraphe. Therefore, it can be solved by using Python SDK. However, it is not a development environment using a GUI like Choregraphe, but it is the same as a normal programming environment. ROS is an open source application development environment for robots. However, since it basically moves on Ubuntu, caution is necessary.

\section{Docking Unit}

\subsection{Overview of extended movement unit}

The extended mobile unit is made up of a mobile robot and a docking unit. The docking unit is a unit for combining with the mobile robot without modifying the body of the Pepper. Figure 3 is an image diagram combining Pepper and extended movement unit. Figure 4 shows the mobile robot for the extended movement unit.

\subsection{Overview of docking unit}

Figure 5 is a view of the docking unit as viewed from above. It consists of three pillars arranged around Pepper and a disk for storing them. The pillar is composed of a plurality of units (extension units), and the disc is fixed with the robot body that has been made. Figure 6 is an enlarged view of the interior of the broken line in Fig. 5. Figure 6 shows a state in which the extension units are stacked up and the pillars are completed. At the time of placing the Pepper on the docking unit, the extension unit is stored in the circular plate, and the column does not exist. In this way, the pillars can be made by sticking and leaving child machines coming in and going out of the circular plate.

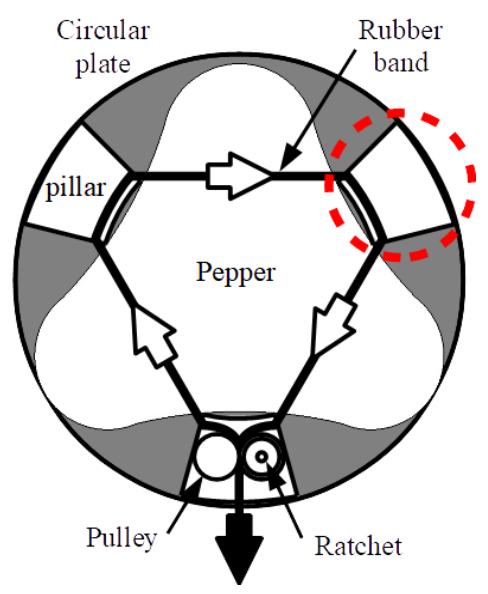

Figure 5. Schematic diagram of docking unit

\subsection{Mobile robot}

The 3D CAD data and the actual image data of the mobile robot are shown in Fig. 4. This mobile robot [10] is a pair of crawler type with tension applied to both side pulleys and tensioned respectively. This makes it possible to move forward, backward and turn. In addition, this robot participated in the 1st Creative Robot Contest for Decommissioning [13], loaded a load of $5 \mathrm{~kg}$ weight, and was able to climb the stairs with a slope of 41 degrees. As a feature of lifting up the stairs, a cylinder was attached to the lower part of the robot for stabilization, but in this study, since it is assumed to run on flat ground at first, there is no cylinder (it was installed for unloading The same applies to the upper cylinder).

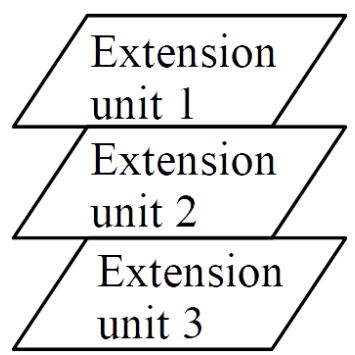

Figure 6. Stacked image of extension unit

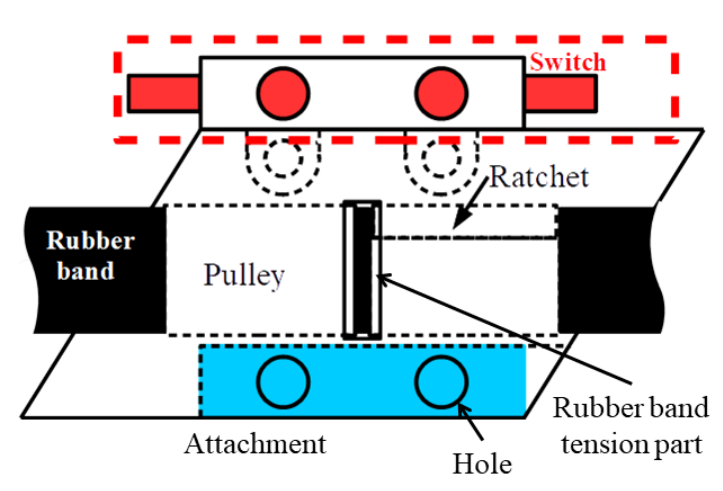

(a) Overall view
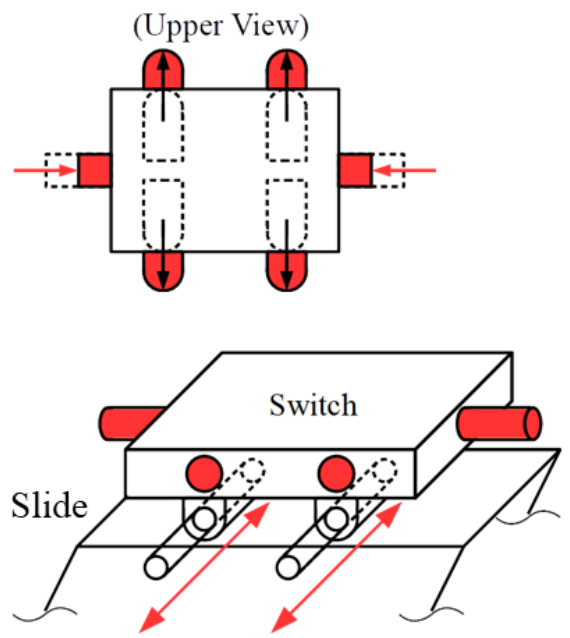

(b) Enlarged view of the connection

Figure 7. Structure diagram of extension unit 


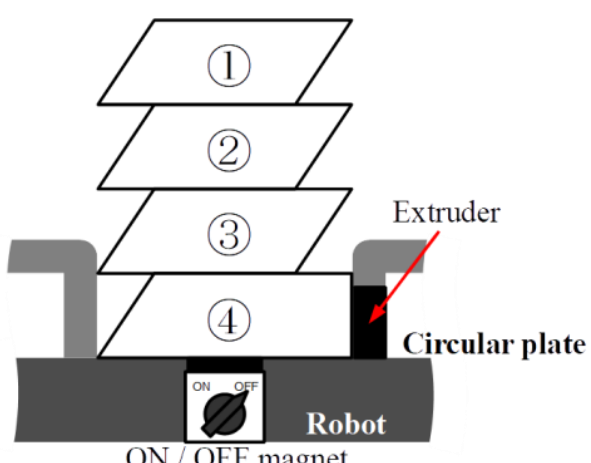

ON / OFF magnet

(a) Mechanism of extruder and pillar fixing method

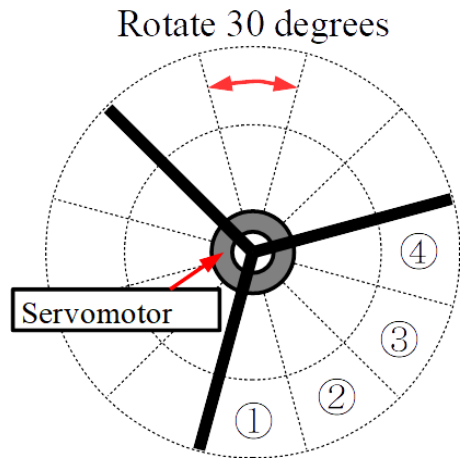

(b) Image diagram of extension unit storage

Figure. 8. Extension unit pushing mechanism and pillar fixing method

Since this robot was not originally designed to carry Pepper, we carried out a test run with a weight of $30 \mathrm{~kg}$ exceeding the weight of Pepper. As a result of the test run, the robot was able to run normally.

The created mobile robot is a robot that moves by autonomous traveling. In the extended mobile unit realized by this research, remote control using a controller is performed. To make the controller and the robot wirelessly communicate, use the PS3 controller for the controller. Wireless communication is realized by attaching a Bluetooth receiver to a single board PC that gives instructions to the actuator of the robot. Since there is no cable between the controller and the extended movement unit, the operator can operate with high degree of freedom.

\subsection{Mechanism of extension unit}

The structure of the extension unit is shown in Fig. 8. When looking at the extension unit from the side, it is a parallelogram, but this is because if you place two extension units, apply one of the extension units to the wall and apply force to the other extension unit from the side, It slides at the hypotenuse of the parallelogram, and the extension unit which applied the force enters under the other, so that the stacking operation becomes possible. The force to be applied is the force obtained by rotating the propeller-type extension unit extruder composed of three servo motors and three plates as shown in Fig. 8 (b) in the circular plate.

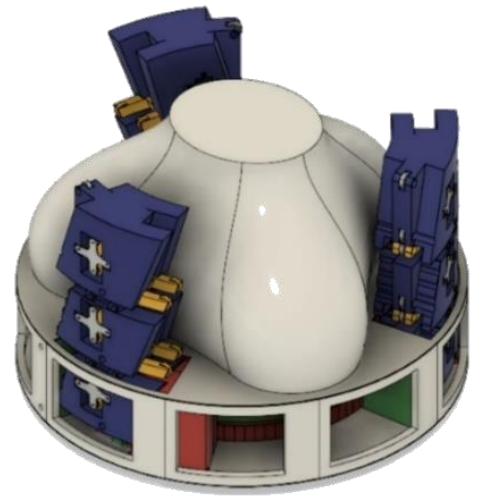

(a) Image of omni wheel robot mounted on the docking unit

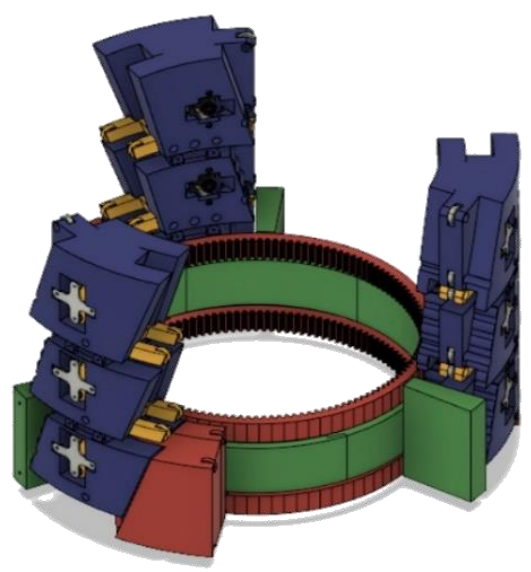

(b) Image excluding omni wheel robot and exterior

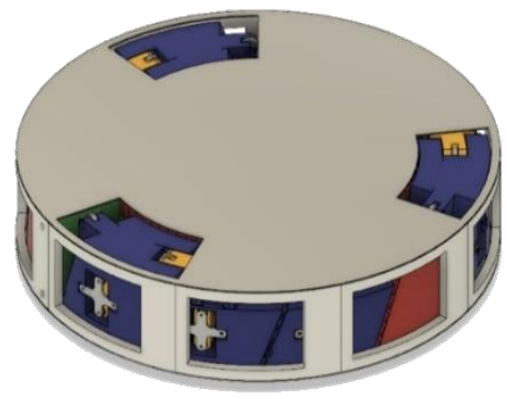

(c) Overall view

Figure 9. 3DCAD images of docking unit

The method of only stacking parallelograms collapses. Therefore, we devised how to connect extension units. Every time the switch in Fig. 7 is pressed, four bars expand and contract from two directions. By this method, handsets connected to each other. Only extension unit located at the bottom of Fig. 5 is constituted by a pulley, a ratchet, and a rubber band pulling portion. Other extension units have a hole through which the rubber band passes on both sides of the main body. The switch section is independent from the extension unit main body and can be slid back and forth. In addition, since the pillar is composed of a plurality of extension units, it is possible to arrange pillars along the curved body line of Pepper. 


\subsection{Fixing method of Pepper using docking unit}

This section shows the procedure of fixing the Pepper using the docking unit. The fixing method is realized by the following six steps.

(1) The extruder rotates clockwise (counterclockwise when stored), and the first extension unit is pushed out from the disk exit.

(2) When rotation of the extruder stops, press the switch to connect the two extension units. In this step, the first stage of the pillar is completed.

(3) Repeat step (1) and step (2) until the four extension units are connected.

(4) Turn on the magnet switch, fix the number 4 of extension unit and Pepper. When the pillar is completed, it becomes as shown in Fig. 8 (a).

(5) Wrap the rubber band around the Pepper in the direction of the white arrow in Fig. 5 and insert it on the ratchet side of the pulley.

(6) Turn the pulley on the ratchet side counterclockwise, and when the rubber band comes out from the rubber band pulling part, pull out in the direction of the black arrow in Fig. 5. When this step is completed, Pepper and the docking unit are fixed.

\section{Creating a Real Model}

\subsection{D CAD images}

We created a 3D model of the docking unit using 3DCAD. Figure 9 shows the 3D CAD images of the docking unit. Figure 9 (a) is a 3D CAD image with an omni wheel robot mounted on the docking unit. Figure 9 (b) is a $3 \mathrm{D}$ CAD image with the omni wheel robot and exterior removed from Fig. 9 (a). Figure 10 shows 3DCAD images of extension unit connection, and Figure 11 does 3DCAD images of extension unit protrusion.

\subsection{Finished product}

We created a real model using the 3D CAD data created in section 4.1. Many parts were created using a 3D printer. Figure 12 (a) shows a picture with the extension unit connection off. Figure 12 (b) shows a picture with the extension unit connection part turned on. Figure 13 shows the state where the protruding part for stably fixing the omni wheel robot protrudes from the extension unit. Figure 14 shows the extension unit connected to the extension unit. The extrusion part and the exterior of the docking unit have not been completed yet.
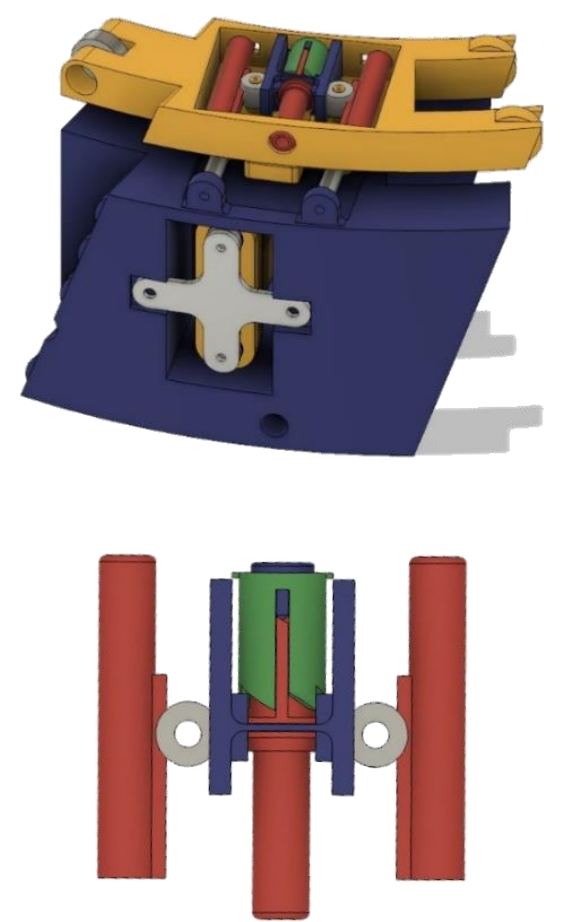

Figure 10. 3DCAD images of extension unit connection
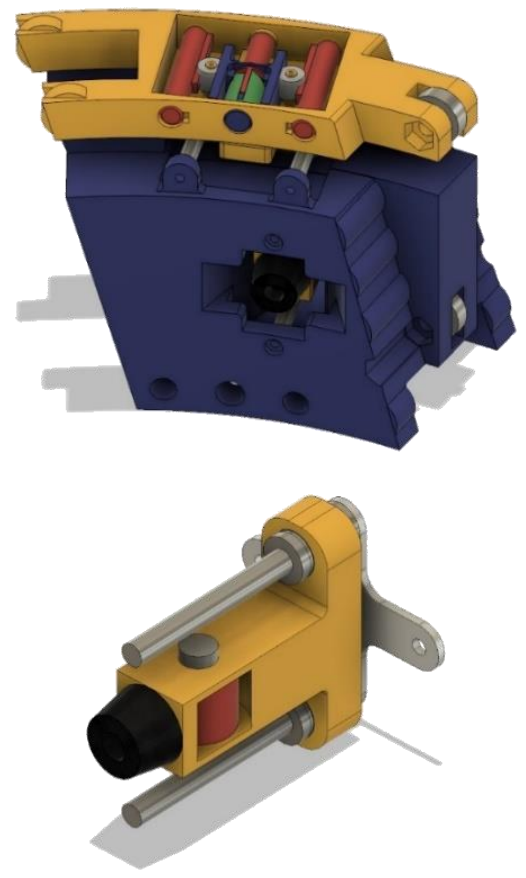

Figure 11. 3DCAD images of extension unit protrusion 


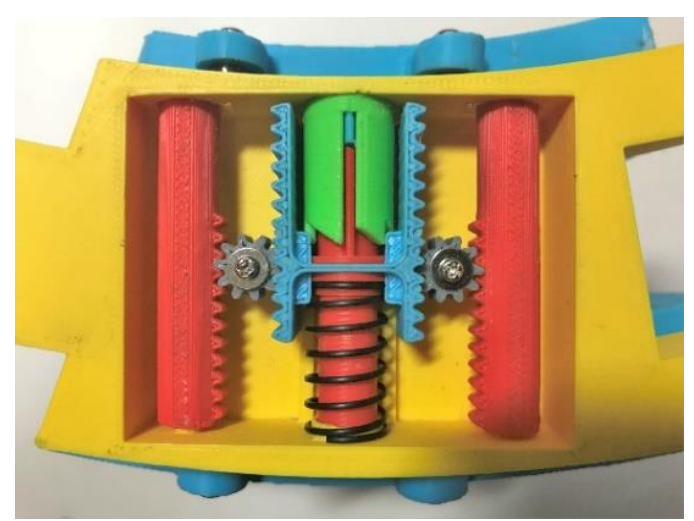

(a) Extension unit connection off

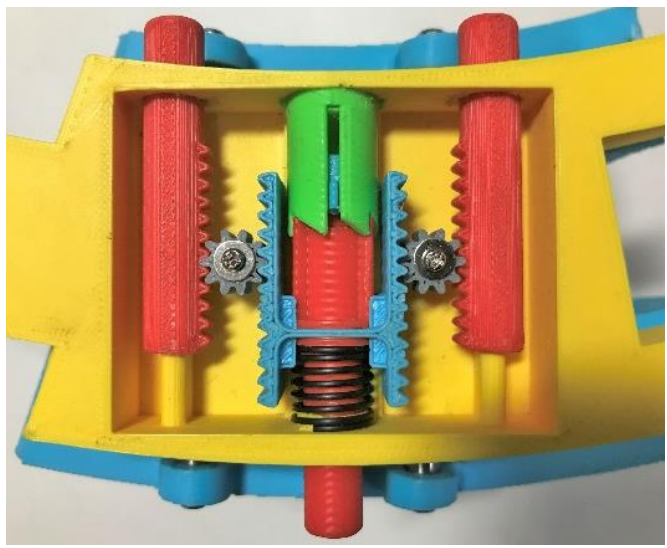

(b) Extension unit connection on

Figure 12. Real model images of extension unit connection
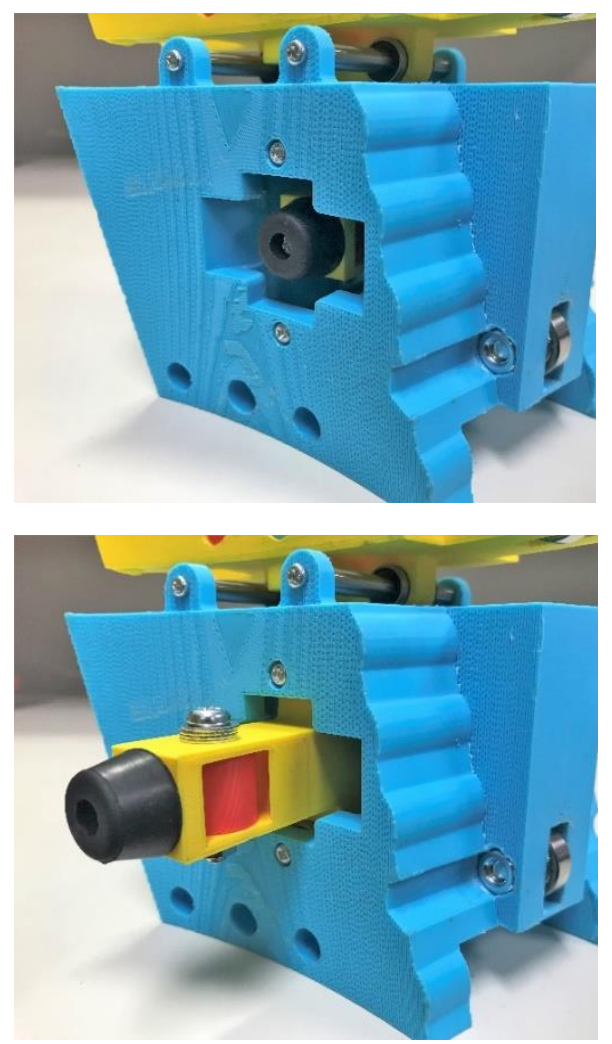

Figure 13. Real model images of extension unit protrusion

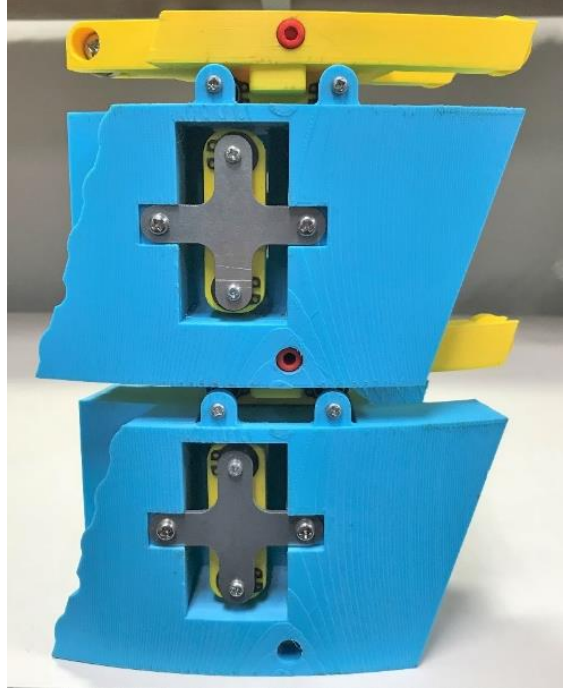

(a) Front view

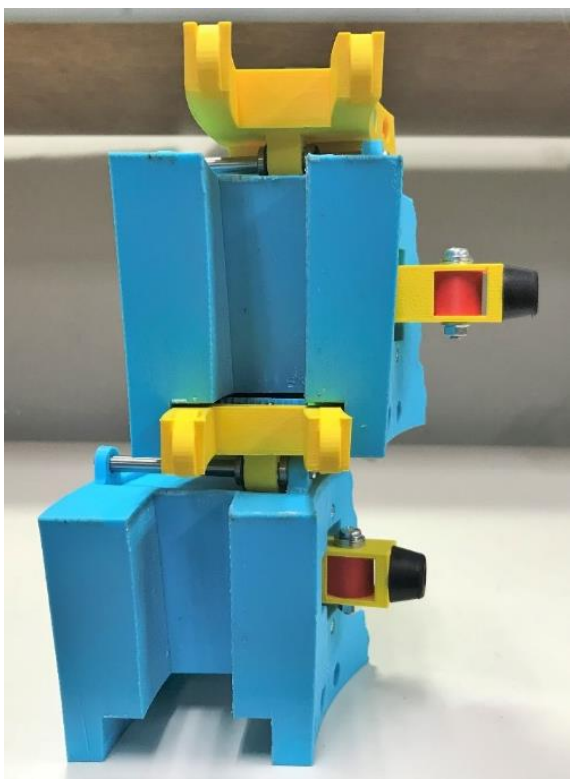

(b) Side view

Figure. 14. Real model images of concatenated extension unit

\section{Conclusions}

Problems existed in the omni wheel robot when the movement area was limited due to the movement device. Therefore, in this research, we aimed to realize an extended movement unit to expand the omni wheel robot of action. The extended movement unit was a unit that can be used without remodeling the omni wheel robot. The extended movement unit consists of a mobile robot that extends mobility and a docking unit that joins the omni wheel robot and mobile robot. The mobile robot was based on the robot we developed. The docking unit is a mechanism that can be joined to the mobile robot without modifying the omni wheel robot.

By docking the extended movement unit and the omni wheel robot in this research, it became possible to move steps and uneven floors that the omni wheel robot had been 
difficult to move until now. The expansion of the omni wheel robot's range of action made it possible for outdoor activities that had been difficult until now.

\section{Acknowledgements}

This research is the result of "The research and education program for the decommissioning technology" carried out under the Center of World Intelligence Project for Nuclear S\&T and Human Resource Development by the Ministry of Education, Culture, Sports, Science and Technology of Japan.

\section{References}

[1] Y. Takase, T. Yoshino, Y. Nakano, "Conversational Robot with Conversation Coordination and Intervention Functionality in Multiparty Conversations," Transactions of Information Processing Society of Japan, 58(5), pp.967-980, 2017.

[2] T. V. Nhu, H. Sawada, "Singing performance of the talking robot with newly redesigned artificial vocal cords," 2017 IEEE International Conference on Mechatronics and Automation (ICMA), pp.665-670, 2017.

[3] B. Salem, "PetRo: Development of a modular pet robot," The 23rd IEEE International Symposium on Robot and Human Interactive Communication, pp.483-488, 2014.

[4] SONY aibo: http://aibo.sony.jp/en/, accessed 01/Nov./2017.
[5] Y. Muramatsu, K. Tokoro, H. Kobayashi, "Development and assessment of muscle suit (Evaluation of the auxiliary operation using the surface EMG)," Transactions of the JSME, Vol. 83(847), p.1600078, 2017.

[6] T. Shibata, "Neurological Therapeutic Seal Robot PARO for Elderly [6] Care," The Journal of the Institute of Electrical Installation Engineers of Japan, 37(9), pp.660-663, 2017.

[7] M. Controzzi, F. Clemente, D. Barone, A. Ghionzoli, C. Cipriani, "The SSSA-MyHand: A Dexterous Lightweight Myoelectric Hand Prosthesis," IEEE Transactions on Neural Systems and Rehabilitation Engineering, 25(5), pp.459-468, 2017.

[8] J. Huang, W. Huo, W. Xu, S. Mohammed, Y. Amirat, "Control of Upper-Limb Power-Assist Exoskeleton Using a Human-Robot Interface Based on Motion Intention Recognition," IEEE Transactions on Automation Science and Engineering, 12(4), pp.1257-1270, 2015.

[9] B. Tang, C. Jiang, H. He, Y. Guo, "Human Mobility Modeling for Robot-Assisted Evacuation in Complex Indoor Environments," IEEE Transactions on Human-Machine Systems, 46(5), pp.694-707, 2016.

[10] P. Di, Y. Hasegawa, S. Nakagawa, K. Sekiyama, T. Fukuda, J. Huang, Q. Huang, "Fall Detection and Prevention Control Using Walking-Aid Cane Robot," IEEE/ASME Transactions on Mechatronics, 21(2), pp.625-637, 2016.

[11] Product specifications of Pepper: https://www. softbank.jp/robot/consumer/products/spec/, accessed 11/Oct./2017.

[12]D. Fujita, R. Yamamoto, S. Mitsui, T. Satake, N. Igo, "U-bo -Robot for 1st Creative Robot Contest for Decommissioning-" Proceedings of The second Conference for R\&D Initiative on Nuclear Decommissioning Technology by the Next Generation, oral session(b)-1,pp.21, 2017.

[13] Creative Robot Contest for Decommissioning: http://www.fukushimanct.ac.jp/ fdecomi/conte5.html, accessed 05/Oct./2017. 